\title{
Article
}

\section{Steroid Regulation of T Cell Function Appears Unaltered in Borderline Personality Disorder}

Fischer, Anja, Grundmann, Johanna, Gold, Stefan M, Spitzer, Carsten and WIngenfeld, Katja

Available at http://clok.uclan.ac.uk/17033/

Fischer, Anja ORCID: 0000-0002-7872-1292, Grundmann, Johanna, Gold, Stefan M, Spitzer, Carsten and WIngenfeld, Katja (2015) Steroid Regulation of $T$ Cell Function Appears Unaltered in Borderline Personality Disorder. Journal of Personality Disorders, 29 (2). ISSN 0885-579X

It is advisable to refer to the publisher's version if you intend to cite from the work. http://dx.doi.org/10.1521/pedi_2014_28_156

For more information about UCLan's research in this area go to http://www.uclan.ac.uk/researchgroups/ and search for <name of research Group>.

For information about Research generally at UCLan please go to http://www.uclan.ac.uk/research/

All outputs in CLoK are protected by Intellectual Property Rights law, including Copyright law. Copyright, IPR and Moral Rights for the works on this site are retained by the individual authors and/or other copyright owners. Terms and conditions for use of this material are defined in the policies page.

\section{CLoK}

Central Lancashire online Knowledge www.clok.uclan.ac.uk

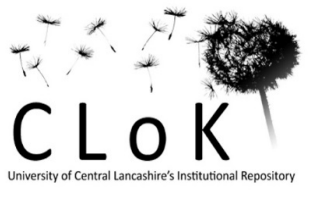




\title{
STEROID REGULATION OF T CELL FUNCTION APPEARS UNALTERED IN BORDERLINE PERSONALITY DISORDER
}

\author{
Anja Fischer, PhD, Johanna Grundmann, MSc, Stefan M. Gold, PhD, \\ Carsten Spitzer, MD, and Katja Wingenfeld, PhD
}

Borderline personality disorder (BPD) is characterized by instability of interpersonal relationships and affection, impulsivity, and cognitive disrup- tions. Increasing evidence suggests hypothalamic-pituitary-adrenal (HPA) axis alterations in BPD. Changed glucocorticoid sensitivity of peripheral blood mononuclear cells is known in mood and posttraumatic stress disor- ders, representing frequent comorbidities in BPD. However, to the authors' knowledge, in BPD glucocorticoid sensitivity at the receptor level remains unexplored. Sixteen age-matched female BPD patients were compared to sixteen female healthy controls. In vitro steroid sensitivity of T cell prolif- eration was tested using aldosterone, dexamethasone, and hydrocortisone. Steroid sensitivity of BPD patients and healthy controls appeared compara- ble. Psychiatric comorbidities such as major depressive disorder or posttrau- matic stress disorder and early life stress seemed to have had no in uence on steroid sensitivity parameters. The data suggest unaltered GC sensitivity of $\mathrm{T}$ cell function in BPD.

Borderline personality disorder (BPD) is characterized by instability of interpersonal relationships and affection as well as cognitive disruptions and impulsivity beginning in early adulthood. It frequently co-occurs with posttraumatic stress disorder (PTSD) and mood disorders, which are characterized by altered stress-response systems such as the hypothalamic-pituitary-adrenal

This article was accepted under the editorship of Robert F. Krueger and John Livesley.

From Institute for Neuroimmunology and Clinical Multiple Sclerosis Research (Inims), Center for Mo- lecular Neurobiology, University Hospital Hamburg-Eppendorf, Hamburg, Germany (A. F., S. M. G.); Department of Psychosomatic Medicine and Psychotherapy, University Medical Center Hamburg-Ep- pendorf and Schön Klinik Hamburg Eilbek, Hamburg, Germany, and Schön Klinik Hamburg-Eilbek, Hamburg, Germany (C. S., K. W.); Asklepios Fachklinikum Tiefenbrunn, Rosdorf, Germany (C. S.); De- partment of Psychiatry and Psychotherapy, University Medical Center Hamburg-Eppendorf (J. G.); and Department of Psychiatry, Charité Campus Benjamin Franklin, Berlin, Germany (K. W.).

Stefan M. Gold is supported by a Heisenberg-Fellowship from the German Research Society (DFG, grant GO 1357/4-1). The research leading to these results has received funding from the European Union Seventh Framework Programme (FP7/2007-2013) [grant number 268381 to Stefan M. Gold]. Katja Wingenfeld receives funding from the German Research Society (DFG). This study was supported by grant WI 3396/2-1. 
The Inims is supported by the Gemeinnützige Hertie-Stiftung.

Address correspondence to Dr. Katja Wingenfeld, Department of Psychiatry, Charité Universitäty Berlin, Campus Benjamin Franklin, Eschenallee 3, 14050 Berlin, Germany; E-mail: katja.wingenfeld@charite.de

(HPA) axis (Wingenfeld, Spitzer, Rullkotter, \& Löwe, 2010). Enhanced basal cortisol concentrations and reduced feedback sensitivity have been frequent- ly but inconsistently reported in BPD. Carvalho Fernando and colleagues (2012) have found evidence for HPA axis involvement in the pathogenesis of BPD, suggesting neuroendocrine similarities to major depressive disor- der (MDD) by means of increased basal cortisol concentrations. But impor- tantly, despite elevated cortisol levels in the dexamethasone suppression test (DST), the hypothesized decrease in glucocorticoid (GC) feedback inhibition was not con rmed. Abnormalities in HPA axis challenge tests (such as the Dex-CRH suppression test) or altered circadian cortisol levels are frequently interpreted as indicators of dysfunction at the receptor level (i.e., glucocorti- coid receptor [GR] or mineralocorticoid receptor [MR]). However, the mul- tiple systems involved in the complex regulatory feedback loop of the HPA axis complicate the interpretation in terms of receptor function. Intriguingly, human lymphocytes express mineralocorticoid and glucocorticoid recep- tors (Armanini, Endres, Kuhnle, \& Weber, 1988) while the immune system is a major target of endogenous glucocorticoids (Baschant \& Tuckermann, 2010). Thus, immune cells can be used to directly examine steroid receptor function ex vivo. This approach has been used to study glucocorticoid sensi- tivity in psychiatric disorders and thus far increased as well as decreased sen- sitivity has been observed (Pariante, 2004; Rohleder, Wolf, \& Wolf, 2010).

To our knowledge, studies of GC sensitivity in the immune system in the context of BPD have not yet been conducted. Therefore, we investigated steroid sensitivity of $\mathrm{T}$ cell responses as a potential biological substrate of BPD.

\section{METHODS}

\section{SUBJECTS}

Age- and education-matched female patients with BPD $(n=16)$ and healthy female control subjects (HC; $n=16$ ) were recruited from the Department of Psychosomatic Medicine and Psychotherapy, Schön Klinik Hamburg Eilbek, or via local advertisement (posters at the University Hospital and via the Department home page) and received nancial remuneration. All subjects 
provided written informed consent. Physical health status was assessed by medical history and careful clinical examination by a staff physician.

Exclusion criteria were a history of severe somatic diseases (e.g., neuro- logical diseases), metabolic diseases (e.g., diabetes), endocrine disorders (e.g., Cushing's syndrome), immune-mediated diseases, hypertension, or current infections. Furthermore, pregnancy, current anorexia, current or lifetime schizophrenia, alcohol or drug dependence, bipolar disorder, schizoaffec- tive disorder, major depression with psychotic symptoms, attention-de cit/ hyperactivity disorder, and cognitive impairment resulted in exclusion. The study was approved by the Ethics Committee of the Chamber of Physicians, Hamburg, Germany.

\section{CLINICAL ASSESSMENTS}

Patients underwent structured clinical interviews administered by trained psychologists (J.G., K.W.) (Structured Clinical Interview for DSM Disor- ders; SCID; First, Spitzer, Gibbon, \& Williams, 1996). Furthermore, patients completed German versions of the Beck Depression Inventory (BDI; Beck, Ward, Mendelson, Mock, \& Erbaugh, 1961), the Posttraumatic Diagnostic Scale (PDS; Foa, 1995), and the Borderline Symptom List (BSL; Bohus et al., 2007). To screen for childhood maltreatment, the German Childhood Trau- ma Questionnaire (CTQ; Klinitzke, Romppel, Häuser, Brähler, \& Glaesmer, 2012) was administered.

\section{STEROID SENSITIVITY ASSAY}

All blood samples were taken between 8:30 and 9:30 a.m. and processed immediately for cryopreservation. Samples were processed according to standard operating procedures of the biobank of the Institute for Neuroimmunology and Clinical Multiple Sclerosis Research (Inims). Peripheral blood mononuclear cells (PBMCs) were isolated using the Ficoll-Hypague method and cryopreserved until assayed. After density centrifugation, PBMCs were resuspended in a stepwise procedure in medium 1 (RPMI-1640 + 10\% FCS) and medium 2 (40\% RPMI-1640, 40\% FCS, 20\% DMSO) at a concentra- tion of $10^{7}$ viable PBMCs per aliquot $(1 \mathrm{~mL})$ and then slowly frozen at an optimal cooling rate of $-1{ }^{\circ} \mathrm{C} /$ minute using Mr. Frosty ${ }^{\circledR}$ freezing containers (ThermoFisher Scienti c, Waltham, MA). After overnight cooling, aliquots were moved to an $\mathrm{N} 2$ storage facility $\left(-180^{\circ} \mathrm{C}\right)$. Using this procedure, vi- ability of cells as 
determined by tryphan blue staining is $>95 \%$ for storage times of up to 5 years. For the current study, maximum storage time was 7 months. Samples from BPD patients and HC were run in parallel using the same batch of reagents. Functional steroid sensitivity of $\mathrm{T}$ cell function was assessed as previously described (Fischer et al., 2012). Cells were seeded at $2 \times 10^{6}$ viable cells $/ \mathrm{mL}$ in RPMI-1640 (PAA Laboratories, Pasching, Austria) supplemented with 2 mM Lglutamine and penicillin/streptomycin and stim- ulated with phytohemagglutinin (PHA) at a concentration of $1 \mu \mathrm{g} / \mathrm{mL}$ alone or in combination with one of seven concentrations of the agonists dexa- methasone $\left(10^{-12} \mathrm{M}\right.$ to $\left.10^{-6} \mathrm{M}\right)$, aldosterone, or hydrocortisone (each $10^{-11} \mathrm{M}$ to $10^{-5} \mathrm{M}$ ). PBMCs were incubated $\left(37^{\circ} \mathrm{C}, 5 \%\right.$ $\mathrm{CO}_{2}$ ) for 48 hours and then pulsed with $1 \mu \mathrm{Ci} /$ well [methyl- ${ }^{3} \mathrm{H}$ ]thymidine. After another 24 hours, cells were harvested with a Tomtec Harvester 96® Mach III M (Tomtec, Inc., Hamden, CT), and thymidine incorporation was determined by liquid scin- tillation (Wallac 1450 microbeta, Trilux, PerkinElmer, Rodgau, Germany). Results were averaged from triplicate wells for each condition expressed as counts per minute (cpm).

\section{STATISTICAL ANALYSIS}

The inhibitory concentration 50 (IC-50) values representing concentrations inhibiting 50\% of the PHA-induced proliferation for each subject and ago-

TABLE 1. Clinical Characteristics as well as Inhibitory Concentration (IC-) 50 for Dexamethasone (DEX), Aldosterone (Aldo), and Hydrocortisone (Cort) of Borderline Personality Disorder (BPD) Patients and Matched Healthy Controls (HC)

\footnotetext{
Age Body height ( $\mathrm{cm}$ ) Weight $(\mathrm{kg})$ Smoking (daily consumption) MDD (y/n) BDI score PTSD (y/n) PDS

score Childhood trauma score

IC-50 Dex [log M]

IC-50 Aldo [log M]

IC-50 Cort [log M]

$\operatorname{BPD}(n=16)$

$26.13+1.12170 .31+1.6062 .84+3.1610 .97+1.8408 / 1621.85+2.8406 / 1621.8+3.9959 .08+5.18(\boldsymbol{n}=\mathbf{1 6})-8.74+0.12$

$-6.30+0.1-7.24+0.12$

HC $(n=16)$

$25.81+1.23169 .31+1.8169 .25+3.476 .19+1.620 / 166.03+1.620 / 167.27+2.9238 .00+2.97(\boldsymbol{n}=\mathbf{1 6})-8.71+0.12-6.2+$
} 
$0.087 .34+0.14$

p value

.72 .52 .14 .06

.00

$.02<.01$

p value $d$.89 0.06 420.03 .590 .02


disorder, PTSD = posttraumatic stress disorder score, yes/no, PDS = Posttraumatic Stress Diagnotic Scale.

nist were determined by nonlinear sigmoidal curve tting utilizing Prism ${ }^{\circledR}$ Software as described by Fischer et al. (2012). All variables were tested for normality and equality of variance. Student $t$ tests were conducted in order to detect differences between the BPD and healthy control (HC) groups us- ing PASW Statistics 18 software, with $p$ values $<0.05$ considered signi cant.

\section{RESULTS}

Patients with BDP and HC were well matched for age, body height, and weight, while there was a marginally signi cant difference for smoking (Ta- ble 1). In the patient group, patients met, on average, six of the DSM-IV cri- teria for BPD. In addition, eight BPD patients met DSM-IV criteria for MDD and six were diagnosed with PTSD (Table 1). Four of these BPD patients had both comorbidities. While seven of the BDP patients were untreated, several participants in the patient group were taking psychotropic medication. These included atypical antipsychotics (Quentiapine, $n=4$; Olanzapine, $n=1$ ) as well as antidepressive treatment (noradrenergic and speci c serotonergic antidepressants, $n_{\text {Mirtazapine }}=1$; Selective serotonin reuptake inhibitors, $n_{\text {Citalopram }}=2$, $n_{\text {Fluoxetine }}=1$; tricyclic antidepressants, $n_{\text {Trimipramine }}=1$; serotonin and norepinephrine reuptake inhibitors, $n_{\text {venlafaxine }}=1$ ). HC were free of psychiatric disorders according to SCID.

As expected, BPD patients had signi cantly higher scores on self-report measures of depression (BDI), childhood trauma (CTQ), and PTSD (PDS) compared to HC. There were no signi cant differences between BPD and HC in T cell steroid sensitivity as measured by IC-50 values with any of the three agonists (see Table 1 and Figure 1). Exploratory analyses revealed 

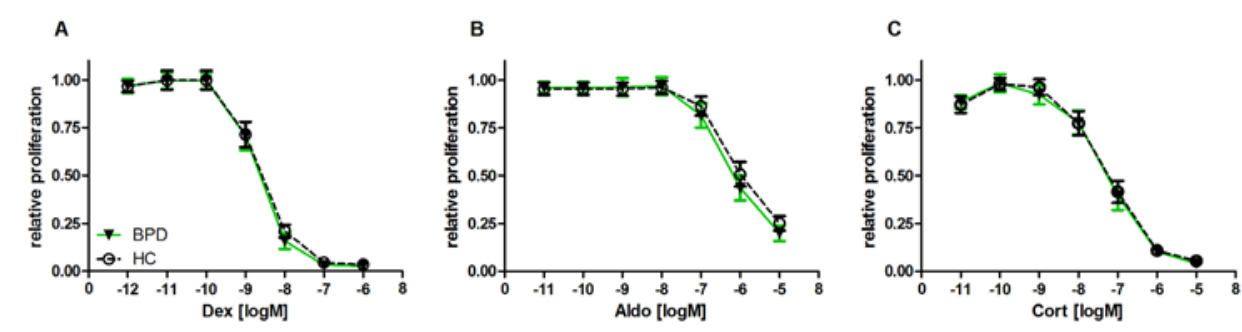

FIGURE 1. Steroid sensitivity in borderline personality disorder and healthy controls. Relative proliferation (counts per minute [cpm]/ PHA control) in the presence of PHA (present in all conditions) and different concentrations of (a) dexamethasone (Dex) (b) aldosterone (Aldo), and (c) hydrocortisone (Cort) both in individuals with Border- line personality disorder (BPD) and in healthy controls (HC).

no correlations between IC-50 values and measures of BPD symptoms as measured by the BSL $\left(p_{\text {dex }}=.68, p_{\text {aldo }}=.32, p_{\text {Cort }}=.99\right)$, depression severity as indicated by BDI scores $\left(p_{\text {dex }}=.79, p_{\text {aldo }}=.38, p_{\text {Cort }}=.94\right)$, the occurrence of childhood trauma according to the CTQ score $\left(p_{\text {dex }}=.32, p_{\text {aldo }}=.77, p_{\text {Cort }}=.93\right)$, or PTSD symptoms (PDS score, $p_{\mathrm{dex}}=.48, p_{\text {aldo }}=.68, p_{\text {Cort }}=.85$ ).

\section{DISCUSSION}

To our knowledge, this is the rst study assessing steroid sensitivity in the immune system in the context of BPD. Our results indicate no apparent alterations in T cell steroid sensitivity in BPD. As expected, MDD and PTSD comorbidity was frequent in the patient group. However, GC sensitivity was not associated with depressive symptoms, PTSD severity, or early life stress (ELS). The cortisol suppression capacity in the DST is considered a mea- sure of the HPA axis GR-mediated negative feedback function. HPA axis hyporesponsiveness with lower basal cortisol levels and pronounced cortisol suppression in the DST have also been reported in BPD, but the majority of studies support the notion of a hyperreactive HPA system (Carvalho Fer- nando et al., 2012). Furthermore, HPA hyperresponsiveness as measured by the DexCRH test was found in BPD patients with a history of chronic abuse in early childhood (Rinne et al., 2002). The authors hypothesized that ELS accounts for this altered HPA state in BPD. Importantly, Carvalho Fernando et al. (2012) have found increased cortisol levels in the DST in BPD, as well as an association between cortisol release and childhood trauma. In contrast to basal and stimulated cortisol (i.e., regulation of the HPA axis itself), we did not nd evidence for an association between childhood trauma and GC sensitivity in 
peripheral immune cells (i.e., a major target tissue of endog- enous glucocorticoids). Our data suggest that GC sensitivity of T cell func- tion is unaltered in BDP, which may indicate a tissue-speci c dysregulation of steroid signaling. In vitro inhibition of cell proliferation has previously been used to reveal differences in GC sensitivity of T cells as a biological substrate of depressive symptoms in patients with multiple sclerosis, a neuro- in ammtory disease of presumably T cell-driven origin (Fischer et al., 2012). Similarly, studies have shown altered GC sensitivity of T cell proliferation in patients with PTSD (de Kloet et al., 2007) and major depression (Lowy, Reder, Gormley, \& Meltzer, 1988; Wodarz et al., 1991). This would suggest that the assay system is speci c and sensitive to pick up GC sensitivity differ- ences in T cell function in autoimmune and psychiatric disorders, but that $\mathrm{T}$ cell regulation by GCs is unaltered in BPD. However, our results do not rule out the possibility that other immune cell subpopulations of the innate (e.g., monocytes, NK cells) or adaptive immune system (e.g., B cells) may show al- tered GC regulation in BPD. This remains to be elucidated with appropriate functional assay systems.

$\mathrm{BPD}$ is a very heterogeneous disorder, and it becomes increasingly clear that comorbidities and clinical features such as trauma history may have variable, interacting in uences on the neuroendocrine pro le in BPD (Zim- merman \& Choi-Kain, 2009). However, GC sensitivity measures were not correlated to severity of depression, severity of PTSD symptoms, or CTQ scores in our study. It has been previously reported that elevated free cor- tisol levels in BPD patients are positively correlated to MDD severity and negatively associated with PTSD symptomatology (Wingenfeld, Driessen, Adam, \& Hill, 2007). In a longitudinal study, DST results were identi ed as a stable marker of abnormal HPA axis function in BPD with comorbid PTSD, resulting in more pronounced suppression (Wingenfeld, Lange, et al., 2007). In another study, it was shown that acute hydrocortisone administra- tion had bene cial effects on hippocampus-relevant memory in BPD, while in healthy controls hydrocortisone impaired memory retrieval (Wingenfeld et al., 2013). These results were interpreted in terms of a cortisol-induced enhancement of hippocampal functioning, which might be related to a sen- sitization of GR function. Possibly, in BPD, altered GR function might be more tissue speci c and restricted to CNS GR (e.g., in the hippocampus and hypothalamus) as well as the pituitary.

The present study has several limitations. Due to the small sample size, lack of 
power is obviously an issue, and the absence of statistically signi cant differences could re ect this fact rather than absence of a biological effect. Therefore, we have also provided effect sizes, which were all well below the accepted thresholds for small effects (Table 1). In addition, the overlapping steroid sensitivity curves and the small error bars observed (Figure 1) argue against a biologically signi cant effect. Given these considerations and the very low effect sizes obtained in this pilot study, we believe that BPD is un- likely to be linked to altered steroid sensitivity of T cell responses. In addi- tion, in this small pilot study, we did not obtain measures of GC regulation in other systems, most notably in the HPA axis itself. Therefore, future studies should assess HPA axis regulation (such as the Dex-CRH test) in parallel with functional assays of GC sensitivity in important target tissues of endog- enous cortisol, such as cells of the innate and adaptive immune system.

In conclusion, our study suggests unaltered GC sensitivity in T cells in BPD, a major compartment of the adaptive immune system.

\section{REFERENCES}

Armanini, D., Endres, S., Kuhnle, U., \& Weber, P. C. (1988). Parallel determination of miner- alocorticoid and glucocorticoid receptors in T- and B-lymphocytes of human spleen. Acta Endocrinologica (Copenhagen), 118, 479-482.

Baschant, U., \& Tuckermann, J. (2010). The role of the glucocorticoid receptor in in am- mation and immunity. Journal of Steroid Biochemistry and Molecular Biology, 120, 69-75.

Beck, A. T., Ward, C. H., Mendelson, M., Mock, J., \& Erbaugh, J. (1961). An inventory for measuring depression. Archives of General Psychiatry, 4, 561-571.

Bohus, M., Limberger, M. F., Frank, U., Chapman, A. L., Kuhler, T., \& Stieglitz, R. D. (2007). Psychometric properties of the Borderline Symptom List (BSL). Psychopathology, 40, 126-132.

Carvalho Fernando, S., Beblo, T., Schlosser, N., Terfehr, K., Otte, C., Lowe, B., . . W Wingen- feld, K. (2012). Associations of childhood trauma with hypothalamic-pituitary-adre- nal function in borderline personality disor- der and major depression. Psychoneuroen- docrinology, 37, 1659-1668.

de Kloet, C. S., Vermetten, E., Bikker, A., Meul- man, E., Geuze, E., Kavelaars, A., . . Hei- jnen, C. J. (2007). Leukocyte glucocorticoid receptor expression and immunoregulation in veterans with and without posttraumat- ic stress disorder. Molecular Psychiatry, 12, 443-453.

First, M. B., Spitzer, R. L., Gibbon, M., \& Wil- liams, J. B. W. (1996). Structured Clinical Interview for DSMIV Axis I Disorders, Clinician Version (SCID-CV). Washington, DC: American Psychiatric Press.

Fischer, A., Otte, C., Krieger, T., Nicholls, R.A., Kruger, S., Ziegler, K. J., . . Gold, S. M. (2012). Decreased hydrocortisone sensitiv- ity of $\mathrm{T}$ cell function in multiple sclerosis- associated major depression. Psychoneuro- 
endocrinology, 37, 1712-1718.

Foa, E. B. (1995). Posttraumatic Stress Diagnostic Scale manual. Minneapolis, MN: National Computer Systems.

Klinitzke, G., Romppel, M., Häuser, W., Brähler, E., \& Glaesmer, H. (2012). Die deutsche Version des Childhood Trauma Question- naire (CTQ)—psychometrische Eigen- schaften in einer bevölkerungsrepräsentativen Stichprobe [The German Version of the Childhood Trauma Questionnaire (CTQ): Psychometric characteristics in a representative sample of the general popu- lation]. Psychotherapie, Psychosomatik, Medizinische Psychologie, 62, 47-51.

Lowy, M. T., Reder, A. T., Gormley, G. J., \& Melt- zer, H. Y. (1988). Comparison of in vivo and in vitro glucocorticoid sensitivity in depression: Relationship to the dexametha- sone suppression test. Biological Psychiatry, 24, 619-630.

Pariante, C. M. (2004). Glucocorticoid receptor function in vitro in patients with major de- pression. Stress, 7, 209-219.

Rinne, T., de Kloet, E. R., Wouters, L., Goekoop, J. G., DeRijk, R .H., \& van den Brink, W. (2002). Hyperresponsiveness of hypotha- lamic-pituitary- adrenal axis to combined dexamethasone/ corticotropinreleasing hormone challenge in female borderline personality disorder subjects with a history of sustained childhood abuse. Biological Psychiatry, 52, 1102-1112.

Rohleder, N., Wolf, J. M., \& Wolf, O. T. (2010). Glucocorticoid sensitivity of cognitive and in ammatory processes in depression and posttraumatic stress disorder. Neuroscience and Biobehavioral Reviews, 35, 104114.

Wingenfeld, K., Driessen, M., Adam, B., \& Hill, A. (2007). Overnight urinary cortisol re- lease in women with borderline personality disorder depends on comorbid PTSD and depressive psychopathology. European Psychiatry, 22, 309-312.

Wingenfeld, K., Driessen, M., Terfehr, K., Schloss- er, N., Fernando, S. C., Otte, C., . . . Wolf, O. T. (2013). Effects of cortisol on memory in women with borderline personality dis- order: Role of co-morbid posttraumatic stress disorder and major depression. Psy- chological Medicine, 43, 495-505.

Wingenfeld, K., Lange, W., Wulff, H., Berea, C., Beblo, T., Saavedra, A. S., . . \& \& Driessen, M. (2007). Stability of the dexamethasone suppression test in borderline personality disorder with and without comorbid PTSD: A one-year follow-up study. Journal of Clinical Psychology, 63, 843-850.

Wingenfeld, K., Spitzer, C., Rullkotter, N., \& Löwe, B. (2010). Borderline personality dis- order: Hypothalamus pituitary adrenal axis and ndings from neuroimaging studies. Psychoneuroendocrinology, 35, 154-170.

Wodarz, N., Rupprecht, R., Kornhuber, J., Schmitz, B., Wild, K., Braner, H. U., \& Riederer, P. (1991). Normal lymphocyte responsiveness to lectins but impaired sensitivity to in vitro glucocorticoids in major depression. Jour- nal of Affective Disorders, 22, 241-248.

Zimmerman, D. J., \& Choi-Kain, L.W. (2009). The hypothalamic-pituitary-adrenal axis in borderline personality disorder: A re- view. Harvard Review of Psychiatry, 17, 167-183. 
